\title{
Digestibilidade da matéria seca de silagens de milho e de suplementos concentrados determinada por procedimentos in vitro
}

\author{
[Dry matter digestibility of corn silages and concentrates determined by in vitro procedures] \\ F.C.F. Lopes $^{1}$, R.A.C. Dornelas ${ }^{1,2}$, J.A.B. Portugal ${ }^{3}$, J.C. Carneiro ${ }^{1}$, R.S. Verneque ${ }^{1}$, \\ J. Silva e Oliveira ${ }^{1}$, P.B. Arcuri ${ }^{1}$, A.C.A. Duque ${ }^{2}$ \\ ${ }^{1}$ Embrapa Gado de Leite \\ Rua Eugênio do Nascimento, 610 \\ 36038-330 - Juiz de Fora, MG \\ ${ }^{2}$ Aluno de graduação - CES-JF - Juiz de Fora, MG \\ ${ }^{3}$ Centro de Ensino Superior de Juiz de Fora - Juiz de Fora, MG
}

\begin{abstract}
RESUMO
Compararam-se os valores de digestibilidade in vitro da matéria seca (DIVMS) de quatro silagens de milho e de seis concentrados (três proteicos e três energéticos), determinados pelo método de dois estádios realizados em tubos individuais ou em equipamento automatizado de fermentação, e avaliou-se a ocorrência de efeito associativo na digestão de alimentos destas três classes incubadas em um mesmo jarro de fermentação da incubadora in vitro, ou em jarros diferentes contendo a mesma classe de alimentos. Utilizou-se delineamento inteiramente ao acaso, em esquema fatorial $3 \times 3$ (procedimentos in vitro $\mathrm{x}$ classes de alimentos). Os valores de DIVMS determinados pelo método dos tubos foram mais próximos dos relatados na literatura e menores $(\mathrm{P}<0,02)$ que os obtidos pelos procedimentos automatizados. Não houve diferença $(\mathrm{P}>0,05)$ nos valores de DIVMS dos concentrados e das silagens de milho incubados no mesmo jarro de fermentação da incubadora ou, separadamente por alimento, em jarros diferentes.
\end{abstract}

Palavras-chave: silagem, concentrado, análise química, composição bromatológica, nutrição de ruminantes

\begin{abstract}
The values of in vitro dry matter digestibility (IVDMD) of four corn silages and six concentrates (three proteic and three energetics) were determined by the two-stage technique that utilizes individual digestion tubes and by an automatic equipment of fermentation (filter bag technique). It was also evaluated the associative effect on digestion of these three food classes when incubated in the same fermentation jar of the "in vitro incubator" and when in different vessels containing the same class of foods. The experimental design was completely

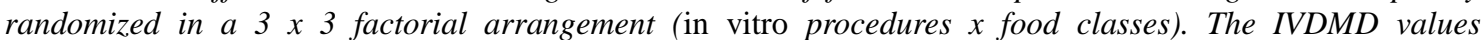
determined in tubes were closer to those found in the literature and lower $(P<0.02)$ than those obtained by the automatic procedure. No differences were found $(P>0.05)$ in IVDMD of concentrates and silages when incubated together in the same fermentation jar or separated by food classes in separated jars.
\end{abstract}

Keywords: silage, concentrate, chemical analysis, ruminant nutrition, bromatological composition

\section{INTRODUÇÃO}

Existem vários métodos para determinação do valor de digestibilidade de alimentos utilizados na formulação de dietas para gado de leite (González et al., 1990; Perez, 1997; Berchielli et al., 2006). O método direto convencional in vivo, por basear-se em ensaios de digestão realizados com animais, é o procedimento de referência e aquele que, preferencialmente, deve ser utilizado para calibração das demais técnicas. No entanto, é oneroso, laborioso e demorado, além de não permitir avaliação simultânea de vários alimentos.

Recebido em 23 de fevereiro de 2009

Aceito em 10 de agosto de 2010

E-mail: fernando@cnpgl.embrapa.br 
Técnicas alternativas mais simples, eficientes, rápidas e de baixo custo vêm sendo desenvolvidas, avaliadas e propostas, visando à determinação de valores de digestibilidade. O procedimento in vitro de dois estágios proposto por Tilley e Terry (1963) para determinação do valor de digestibilidade de alimentos, a despeito de limitações (Ayres, 1991; Adesogan, 2002), é o mais difundido e utilizado em estudos de nutrição de ruminantes (Berchielli et al., 2006). No entanto, apresenta restrições de ordem prática, principalmente às relacionadas ao excesso de tempo e trabalho despendidos com as etapas químico-microbiológicas da análise, bem como à necessidade metodológica de que cada alimento avaliado na bateria seja incubado individualmente em tubos, o que limita sobremaneira sua eficiência na utilização da mão de obra especializada e dos recursos financeiros e de infraestrutura do laboratório.

Equipamentos automatizados de determinação de digestibilidade in vitro estão sendo atualmente comercializados com a promessa de redução dos custos e dos trabalhos de manipulação de amostras, que são coletivamente fermentadas em jarros de digestão, ao invés de individualmente incubadas em tubos, como no procedimento tradicional de Tilley e Terry (1963). Além do mais, permitem economia de espaço no laboratório e aumentam a segurança dos laboratoristas pela redução na manipulação de reagentes (Vogel et al., 1999).

Vários autores recomendaram o uso de sistemas automatizados de fermentação in vitro na determinação de valores de digestibilidade da matéria seca (Traxler et al., 1995; Holden, 1999; Mabjeesh et al., 2000; Adesogan, 2005). Wilman e Adesogan (2000) relataram que o método tradicional, em que a incubação dos alimentos foi realizada em tubos individuais, produziu resultados com menores erros-padrão e coeficientes de variação que os observados no sistema automatizado de fermentação in vitro. Em diversos trabalhos, valores de digestibilidade determinados em sistemas automatizados de fermentação foram superestimados (Vogel et al., 1999; Figueiredo et al., 2000; Mabjeesh et al., 2000; Santos et al., 2000; Wilman e Adesogan, 2000; Damiran et al., 2002) ou subestimados (Adesogan, 2005) em relação aos obtidos de métodos tradicionais realizados em tubos individuais.
Os resultados de digestibilidade obtidos a partir de equipamentos automatizados de fermentação in vitro podem ser afetados por inúmeros fatores, dentre os quais se pode citar a potencial ocorrência de efeito associativo na digestão de amostras incubadas em um mesmo jarro de fermentação (Adesogan, 2005). Wilman e Adesogan (2000) concluíram que o escape de compostos solúveis de amostras com elevadas concentrações destas substâncias poderia influenciar a população microbiana e, desta forma, aumentar a degradação da parede celular de alimentos com baixo teor destas substâncias e incubados no mesmo jarro de fermentação. No entanto, Holden (1999) não observou diferença $(\mathrm{P}>0,05)$ nos valores de digestibilidade in vitro da matéria seca de diversos alimentos volumosos e concentrados, quando incubados no mesmo jarro de fermentação ou em jarros de fermentação diferentes.

Foi objetivo deste experimento comparar valores de digestibilidade in vitro da matéria seca de silagens de milho e de suplementos concentrados proteicos e energéticos, determinados pelo procedimento de dois estágios de Tilley e Terry (1963) ou em equipamento automatizado de fermentação, bem como avaliar a ocorrência de efeito associativo na digestão de alimentos dessas três classes de alimentos, incubados em um mesmo jarro de fermentação da "incubadora in vitro" ou em jarros diferentes contendo alimentos pertencentes à mesma classe.

\section{MATERIAL E MÉTODOS}

Utilizou-se delineamento inteiramente ao acaso e foram comparados três procedimentos de determinação da digestibilidade in vitro da matéria seca (DIVMS): 1) tradicional, de dois estágios (Tilley e Terry, 1963); 2) automatizado, utilizando-se incubadora in vitro modelo TE-150 (Tecnal Equipamentos para Laboratório, Piracicaba, SP), em que alimentos concentrados (proteicos e energéticos) e volumosos (silagens de milho) foram incubados em sacos confeccionados em TNT-100 (Tecido-não tecido, $100 \%$ polipropileno, dimensões $5,5 \times 5,5 \mathrm{~cm}$ ), e colocados em um mesmo jarro de fermentação; 3) automatizado, mas incubando-se os sacos contendo cada uma das três classes de alimentos (concentrados proteicos e energéticos e silagens de milho) nos respectivos três jarros de fermentação restantes da incubadora in vitro. 
Utilizou-se esquema fatorial 3 x 3 (três procedimentos in vitro de determinação da DIVMS $\mathrm{x}$ três classes de alimentos), e os alimentos avaliados (Tab. 1) foram quatro silagens de milho, três concentrados proteicos (farelos de soja e de algodão, e grão de soja) e três concentrados energéticos (fubá de milho, farelo de trigo e polpa cítrica).

Todas as amostras de alimentos foram présecadas por $72 \mathrm{~h}$ em estufa de ventilação forçada, regulada para $55^{\circ} \mathrm{C}$, sendo, posteriormente, moídas em moinho de facas dotado de peneira com abertura de malhas de $1 \mathrm{~mm}$, e analisadas quanto aos teores de matéria seca (MS), proteína bruta $(\mathrm{PB})$, fibra em detergente neutro (FDN) e fibra em detergente ácido (FDA), segundo métodos descritos por Silva e Queiroz (2002).
No procedimento in vitro de dois estágios de Tilley e Terry (1963), os 10 alimentos foram incubados em duplicata em tubos contendo $50 \mathrm{~mL}$ de solução tamponada $(\mathrm{pH}$ final $=6,69)$, preparada utilizando-se a relação $4: 1(\mathrm{v} / \mathrm{v})$ de saliva artificial e inóculo ruminal. Dois tubos contendo somente a solução tamponada ("prova em branco") e dois tubos com amostra de forragem de digestibilidade conhecida ("alimento-padrão") foram incluídos à bateria. Depois de $48 \mathrm{~h}$ de incubação, $4 \mathrm{~mL}$ de ácido clorídrico $(\mathrm{HCl})$ a $7,4 \%(\mathrm{v} / \mathrm{v})$ e $2 \mathrm{~mL}$ de pepsina $1: 10.000$ a $5 \%(\mathrm{p} / \mathrm{v})$ foram adicionados a cada tubo e, após novo período de $48 \mathrm{~h}$ de incubação, foram realizados os procedimentos de filtragem a vácuo, secagem $\left(105^{\circ} \mathrm{C}\right)$ e pesagem dos resíduos, visando aos cálculos de digestibilidade in vitro da MS (Silva e Queiroz, 2002).

Tabela 1. Composição química dos alimentos volumosos e concentrados avaliados no estudo

\begin{tabular}{|c|c|c|c|}
\hline \multirow{3}{*}{ Alimento } & \multicolumn{3}{|c|}{ Composição química $^{1}$} \\
\hline & PB & FDN & FDA \\
\hline & \multicolumn{3}{|c|}{ (\% da matéria seca) } \\
\hline \multicolumn{4}{|c|}{ Silagem de milho } \\
\hline Híbrido duplo, grão semiduro & 9,5 & 51,0 & 41,0 \\
\hline Híbrido triplo, grão dentado & 10,2 & 41,5 & 37,6 \\
\hline Híbrido triplo, grão duro & 10,7 & 49,1 & 37,3 \\
\hline Híbrido duplo, grão duro & 9,1 & 45,5 & 38,4 \\
\hline \multicolumn{4}{|c|}{ Concentrado proteico } \\
\hline Farelo de soja & 50,2 & 9,8 & - \\
\hline Farelo de algodão & 40,4 & 31,8 & 22,5 \\
\hline Grão de soja & 33,8 & 14,5 & - \\
\hline \multicolumn{4}{|c|}{ Concentrado energético } \\
\hline Fubá de milho & 10,4 & 6,9 & 3,5 \\
\hline Farelo de trigo & 17,8 & - & - \\
\hline Polpa cítrica & 6,6 & 18,9 & - \\
\hline
\end{tabular}

${ }^{1}$ PB: proteína bruta; FDN: fibra em detergente neutro; FDA: fibra em detergente ácido.

No método automatizado, no tratamento em que os seis alimentos concentrados e os quatro volumosos foram incubados em um mesmo jarro de fermentação da incubadora in vitro, foram utilizadas duas réplicas por alimento, além de dois sacos vazios ("prova em branco") e dois contendo o "alimento-padrão", totalizando 24 sacos no jarro de fermentação, que continha $1.200 \mathrm{~mL}$ da mesma solução tamponada relatada para o tratamento realizado nos tubos. Depois de $48 \mathrm{~h}$ de incubação, foram adicionados $96 \mathrm{~mL}$ de $\mathrm{HCl}$ a $7,4 \%(\mathrm{v} / \mathrm{v})$ e $48 \mathrm{~mL}$ de pepsina 1:10.000 a $5 \%(\mathrm{p} / \mathrm{v})$, e após novo período de $48 \mathrm{~h}$ de incubação, foram realizados os procedimentos de lavagem, secagem $\left(105^{\circ} \mathrm{C}\right)$ e pesagem dos sacos, visando aos cálculos de DIVMS (Ankom..., 2006).

No tratamento em que se procedeu à incubação de cada uma das três classes de alimentos em diferentes jarros de fermentação da incubadora in vitro, foram utilizadas seis réplicas por alimento, além de três sacos vazios ("prova em branco") e três contendo o "alimento-padrão", totalizando 24 sacos em cada um dos três jarros de fermentação. Os demais procedimentos foram realizados conforme relatado para o tratamento anterior.

Para fornecimento de líquido ruminal, foi utilizada uma vaca Holandês x Zebu, fistulada no 
rúmen e dotada de cânula de borracha com $110 \mathrm{~mm}$ de diâmetro interno de abertura (Kehl Ind. Com. Ltda. - São Carlos, SP, Brasil). A vaca recebeu dieta baseada em silagem de milho ad libitum, e os procedimentos de coleta e de processamento do líquido ruminal foram os rotineiramente adotados pelo Laboratório de Digestibilidade da Embrapa Gado de Leite, seguindo as recomendações de Silva e Queiroz (2002). A solução tamponada dispensada nos tubos de incubação e nos quatro jarros de fermentação da incubadora in vitro foi obtida de uma mesma alíquota, processada em quantidade suficiente para atender à demanda do experimento. Da mesma forma, as soluções de pepsina e de $\mathrm{HCl}$ foram as mesmas utilizadas nos três procedimentos in vitro avaliados. Independentemente do método de análise de DIVMS, a temperatura de incubação foi mantida em $39^{\circ} \mathrm{C}$. Os três procedimentos de incubação in vitro foram repetidos no tempo, duplicando o número de réplicas por tratamento.

O experimento foi analisado pelo procedimento GLM do SAS... (1997). Os valores de DIVMS determinados pelo método tradicional de dois estágios de Tilley e Terry (1963) foram comparados aos obtidos dos dois procedimentos de incubação realizados na incubadora in vitro, que também foram comparados entre si por meio de contrastes ortogonais $(\mathrm{P}<0,05)$. Para comparação das médias $(\mathrm{P}<0,05)$, utilizou-se o LSMEANS do SAS/1997.

\section{RESULTADOS E DISCUSSÃO}

Na Tab. 2, são apresentados os valores médios de DIVMS, determinados pelos três procedimentos in vitro para os 10 alimentos avaliados no estudo.

Tabela 2. Médias e desvios-padrão dos valores de digestibilidade da matéria seca (\%) dos suplementos concentrados e das silagens de milho, determinados utilizando-se três procedimentos in vitro

\begin{tabular}{lccc} 
& \multicolumn{3}{c}{ Procedimento in vitro } \\
\cline { 2 - 4 } Classe/Alimento & $\begin{array}{c}\text { Tilley e Terry } \\
\text { (1963) }\end{array}$ & $\begin{array}{c}\text { Alimento incubado no } \\
\text { mesmo jarro de } \\
\text { fermentação }\end{array}$ & $\begin{array}{c}\text { Alimento incubado em } \\
\text { diferentes jarros de } \\
\text { fermentação }\end{array}$ \\
\hline Híbrido duplo, grão semiduro & $56,8 \pm 2,26$ & Silagem de milho & $71,8 \pm 2,15$ \\
Híbrido triplo, grão dentado & $57,6 \pm 1,64$ & $72,2 \pm 1,42$ & $73,0 \pm 2,43$ \\
Híbrido triplo, grão duro & $61,1 \pm 3,30$ & $72,9 \pm 2,20$ & $71,6 \pm 1,74$ \\
Híbrido duplo, grão duro & $65,0 \pm 2,69$ & $74,5 \pm 1,62$ & $75,0 \pm 1,92$ \\
\hline & Concentrado proteico & \\
Farelo de soja & $93,9 \pm 0,87$ & $93,8 \pm 1,49$ & $91,7 \pm 3,94$ \\
Farelo de algodão & $63,1 \pm 0,20$ & $74,6 \pm 1,78$ & $65,9 \pm 7,62$ \\
Grão de soja & $68,2 \pm 4,26$ & $94,1 \pm 0,38$ & $85,9 \pm 3,67$ \\
\hline & Concentrado energético & $89,2 \pm 4,16$ \\
\hline Fubá de milho & $81,9 \pm 7,10$ & $96,5 \pm 1,32$ & $72,2 \pm 1,86$ \\
Farelo de trigo & $70,0 \pm 2,05$ & $77,0 \pm 3,28$ & $91,8 \pm 5,06$ \\
Polpa cítrica & $91,0 \pm 1,72$ & $94,9 \pm 1,17$ & \\
\hline
\end{tabular}

De modo geral, os valores de digestibilidade da MS das silagens e do fubá de milho determinados pelo método de dois estágios de Tilley e Terry (1963) foram mais próximos dos relatados na literatura (Morais et al., 1999; Valadares Filho et al., 2000) do que os obtidos do equipamento automatizado de fermentação in vitro. Para a polpa cítrica, todos os métodos superestimaram os valores de 71,9 a $89,0 \%$ de digestibilidade aparente da MS apresentados por Bampidis e Robinson (2006). Da mesma forma, para o farelo de soja, todos os valores determinados foram mais elevados que o relatado por Valadares Filho et al. (2000). Para o grão de soja e os farelos de trigo e de algodão, os valores de DIVMS determinados quando os alimentos foram incubados no mesmo jarro de fermentação da incubadora in vitro foram, de modo geral, mais altos que os obtidos nos demais procedimentos, bem como em relação àqueles apresentados por Valadares Filho et al. (2000).

Nos trabalhos realizados por Traxler et al. (1995) 
e Wilman e Adesogan (2000), foram relatados menores desvios-padrão nos valores de DIVMS determinados por métodos tradicionais realizados em tubos individuais em relação aos obtidos de sistemas automatizados de fermentação. No entanto, conforme apresentado na Tab. 2, não houve evidência de maior precisão de um procedimento in vitro em detrimento dos demais, haja vista que, em função do alimento avaliado, houve variações nos desvios-padrão das médias de DIVMS.
Na Tab. 3, em função da classe de alimentos, são apresentados os valores médios de DIVMS, determinados pelo método tradicional de dois estágios de Tilley e Terry (1963), ou pelo uso da incubadora in vitro.

Foram observados efeitos de classe de alimentos $(\mathrm{P}<0,002)$ e do procedimento de determinação da DIVMS $(\mathrm{P}<0,035)$. No entanto, não houve efeito da interação dos fatores estudados $(\mathrm{P}>0,05)$.

Tabela 3. Digestibilidade da matéria seca $(\%)$ segundo o procedimento in vitro em diferentes classes de alimentos

\begin{tabular}{lcccc} 
& \multicolumn{4}{c}{ Procedimento in vitro } \\
\cline { 2 - 4 } Classe de alimento & $\begin{array}{c}\text { Tilley e Terry } \\
(1963)\end{array}$ & $\begin{array}{c}\text { Alimento incubado no } \\
\text { mesmo jarro de } \\
\text { fermentação }\end{array}$ & $\begin{array}{c}\text { Alimento incubado } \\
\text { em diferentes jarros } \\
\text { de fermentação }\end{array}$ & EPM \\
\hline Silagens de milho & $60,1 \mathrm{a}$ & $73,1 \mathrm{~b}$ & $72,8 \mathrm{~b}$ & 4,85 \\
Concentrados proteicos & $75,1 \mathrm{a}$ & $89,1 \mathrm{~b}$ & $81,2 \mathrm{~b}$ & 5,60 \\
Concentrados energéticos & $81,0 \mathrm{a}$ & $89,4 \mathrm{~b}$ & $84,4 \mathrm{~b}$ & 5,60 \\
\hline
\end{tabular}

Letras distintas na mesma linha indicam diferença $(\mathrm{P}<0,002)$ entre procedimentos de determinação de digestibilidade in vitro.

EPM: erro-padrão da média.

Os valores de DIVMS determinados pelo método de Tilley e Terry (1963) foram consistentemente inferiores $(\mathrm{P}<0,019)$ aos obtidos dos dois procedimentos de incubação realizados na incubadora in vitro (Tab. 3), confirmando os trabalhos de Vogel et al. (1999), Figueiredo et al. (2000), Mabjeesh et al. (2000), Santos et al. (2000), Wilman e Adesogan (2000) e Damiran et al. (2002). Ao utilizar-se a incubadora in vitro, os valores de DIVMS do "alimento-padrão" foram superestimados em relação ao valor real, enquanto na incubação realizada nos tubos obteve-se boa concordância entre esses valores. Os resultados de digestibilidade obtidos a partir de equipamentos automatizados de fermentação in vitro podem ser afetados pelo tamanho de amostra incubada, pelo método de processamento, pela proximidade dos jarros de incubação em relação à fonte de calor, pelas diferenças na extensão pela qual cada saco contendo a amostra encontra-se imerso na solução tamponada de inóculo ruminal e pela potencial ocorrência de efeito associativo na digestão de alimentos incubados em um mesmo jarro de fermentação (Adesogan, 2002; 2005).

Quanto a este último efeito, Wilman e Adesogan (2000) concluíram que o escape de compostos solúveis de amostras com elevadas concentrações destas substâncias poderia influenciar a população microbiana e, dessa forma, aumentar a degradação da parede celular de alimentos com baixo teor desses nutrientes e incubados no mesmo jarro de fermentação. No entanto, no presente estudo, não foi observada diferença ( $\mathrm{P}>0,05)$ nos valores de DIVMS dos suplementos concentrados e das silagens de milho, quando incubados no mesmo jarro do equipamento automatizado de fermentação ou, separadamente por alimento, em jarros diferentes. Holden (1999) também não observou diferença $(\mathrm{P}>0,05)$ nos valores de DIVMS de diversos alimentos volumosos e concentrados, quando incubados no mesmo jarro de fermentação ou em jarros de fermentação diferentes.

No entanto, pelos dados apresentados nas Tab. 2 e 3, pode-se observar que a maior amplitude na diferença entre os valores de DIVMS determinados nos dois procedimentos de incubação realizados na incubadora in vitro ocorreu entre as amostras de suplementos concentrados, notadamente para o farelo de algodão, o grão de soja, o fubá de milho e o farelo de trigo. Ademais, os valores de DIVMS 
destes suplementos foram sempre numericamente maiores no tratamento em que as três classes de alimentos foram incubadas em conjunto no mesmo jarro de fermentação, o que sugere que pode ter havido algum efeito associativo na digestão das amostras, embora não detectado na análise estatística.

No presente estudo, o material utilizado na confecção dos sacos de incubação foi o TNT100. Entretanto, aquele considerado referência em estudos de digestibilidade in vitro realizados em equipamento automatizado de fermentação é o F-57, com porosidade de $25 \mu$ (Ankom Technology, Macedon, NY, EUA) que, no entanto, apresenta custo elevado. Resultados de trabalhos que visavam avaliar o efeito da utilização de material alternativo na confecção dos sacos de incubação, de modo geral, evidenciaram maiores $(\mathrm{P}<0,05)$ valores de DIVMS, principalmente por estes apresentarem tamanho de poros superior ao do F-57 (Oliveira e Morgan, 2002; Adesogan, 2005). Segundo Adesogan (2005), isso pode facilitar a colonização e a digestão dos alimentos pelos microrganismos ruminais, bem como permitir maior efluxo de pequenas partículas não digeridas das amostras incubadas.

Ao trabalharem com feno de alfafa (Medicago sativa, L.) e utilizarem equipamento automatizado de fermentação in vitro, Ribeiro e Oliveira (2004) relataram que valores de DIVMS obtidos de amostras incubadas em sacos confeccionados com TNT-100 foram superiores $(\mathrm{P}<0,01)$ aos determinados nos sacos F-57. No entanto, mesmo adotando os sacos F-57 em sistema automatizado de fermentação, Santos et al. (2000) relataram que valores de DIVMS de três das cinco gramíneas tropicais avaliadas em seu estudo foram superestimados $(\mathrm{P}<0,05) \mathrm{em}$ relação aos obtidos por meio do método tradicional realizado em tubos. Isto evidencia que aspectos adicionais ao tipo de material utilizado na confecção dos sacos de incubação podem também estar influenciando nos resultados superestimados de DIVMS, determinados em equipamentos automatizados de fermentação.

No presente estudo, observou-se que os sacos confeccionados com TNT-100 frequentemente desfiavam-se, facilitando a adesão de partículas suspensas da solução tamponada.

\section{CONCLUSÕES}

A não ocorrência de efeito associativo na digestão de silagens de milho e de concentrados permite a incubação conjunta dos alimentos e otimiza a utilização da mão de obra especializada e dos recursos financeiros, materiais e de infraestrutura do laboratório na determinação de digestibilidade in vitro. A superestimativa dos valores de digestibilidade in vitro da matéria seca de alimentos volumosos e concentrados comumente utilizados na dieta de ruminantes condiciona a recomendação do emprego do equipamento automatizado à implementação de novos estudos, com ênfase nos relacionados ao material de confecção dos sacos de incubação.

\section{AGRADECIMENTOS}

Ao Centro de Ensino Superior de Juiz de Fora (CES-JF), pela concessão de bolsa de iniciação científica ao autor R.A.C. Dornelas. À Embrapa Gado de Leite, pela concessão de estágio à autora A.C.A. Duque. A José Moreira de Castilho, pelo auxílio nos ensaios de digestibilidade. À Fundação de Amparo à Pesquisa do Estado de Minas Gerais FAPEMIG, pelo apoio financeiro ao trabalho.

\section{REFERÊNCIAS BIBLIOGRÁFICAS}

ADESOGAN, A.T. Effect of bag type on the apparent digestibility of feeds in ANKOM Daisy ${ }^{\text {II }}$ incubators. Anim. Feed Sci. Technol., v.119, p.333-344, 2005.

ADESOGAN, A.T. What are feeds worth?: A critical evaluation of selected nutritive vlues methods. In: ANNUAL FLORIDA RUMINANT NUTRITION SYMPOSIUM, 13., 2002, Gainesville. Proceedings... Gainesville: University of Florida, 2002. p.33-47.

ANKOM TECHNOLOGY. Daisy II Incubator Overview - Application \& Information. Macedon, NY, EUA, 2006. Disponível em: <http://www.ankom.com/00_products/product_d aisy.shtml>. Acesso em: 2 dez. 2006.

AYRES, J.F. Sources of error with in vitro digestibility assay of pasture feeds. Grass Forrage Sci., v.46, p.89-97, 1991.

BAMPIDIS, V.A.; ROBINSON, P.H. Citrus byproducts as ruminants feeds: a review. Anim. Feed. Sci. Technol., v.128, p.175-217, 2006. 
BERCHIELLI, T.T.; GARCIA, A.V.; OLIVEIRA, S.G. Principais técnicas de avaliação em estudo de nutrição. In: BERCHIELLI, T.T.; VAZ PIRES, A.; OLIVEIRA, S.G. (Eds). Nutrição de ruminantes. Jaboticabal: Funep, 2006. p.397-421.

DAMIRAN, D.; DelCURTO, T.; BOHNERT, D.W. Comparison of techniques and grind size to estimate digestibility of forage base ruminant diets. In: WESTERN SECTION OF AMERICAN SOCIETY OF ANIMAL SCIENCE, 53., 2002, Colorado. Proceedings... Colorado: Oregon State University, 2002. p.341344.

FIGUEIREDO, M.; MBHELE, A.; ZONDI, J. A modification of the Daisy II-220 technique for determing in vitro digestibility of animal feeds in comparison with the Minson \& McLeod Technique. S. Afr. J. Anim. Sci., v.30, suppl. 1, p.45-46, 2000.

GONZÁLEZ, D.; RUIZ, M.E.; ROMERO, F. et al. Recomendaciones sobre la utilización de los metodos in vitro, in situ y enzimatico en el estudio de la digestión de alimentos. In: RUIZ, M.E.; RUIZ, A. (Eds). Nutrición de rumiantes: Guía metodológica de investigación. San José, Costa Rica: IICA-ALPA-RISPAL, 1990. p.127-146.

HOLDEN, L.A. Comparison of methods of in vitro dry matter digestibility for ten feeds. $J$. Dairy Sci., v.82, p.1791-1794, 1999.

MABJEESH, S.J.; COHEN, M.; ARIELI, A. In vitro methods for measuring the dry matter digestibility of ruminant feedstuffs: comparison of methods and inoculum sources. J. Dairy Sci., v.83, p.2289-2294, 2000.

MORAIS, M.G.; TOMICH, T.R.; AMORIM NETO, J.R.P. et al. Consumo voluntário e digestibilidade da silagem de milho associada ao esterco de poedeiras. Arq. Bras. Med. Vet. Zootec., v.51, p.115-119, 1999.

OLIVEIRA, M.D.S.; MORGAN, V.C. Efeito do tipo de material utilizado na confecção dos sacos de fermentação sobre a degradabilidade ruminal in vitro da matéria seca pelo fermentador ruminal Daisy II. ARS Veterinária, v.18, p.88-93, 2002.
PEREZ, J.R.O. Sistemas para a estimativa de digestibilidade in vitro. In: SIMPÓSIO INTERNACIONAL DE DIGESTIBILIDADE EM RUMINANTES, 1997, Lavras. Anais... Lavras: UFLA-FAEPE, 1997. p.55-68.

RIBEIRO, G.M.; OLIVEIRA, M. Dal. S. Digestibilidade in vitro do feno de alfafa obtida no fermentador ruminal Daisy II. In: REUNIÃO ANUAL DA SOCIEDADE BRASILEIRA DE ZOOTECNIA, 41., 2004, Campo Grande. Anais... Campo Grande: SBZ, 2004. CD-ROM.

SANTOS, G.T.; ASSIS, M.A.; GONÇALVES, G.D. et al. Determinação da digestibilidade in vitro de gramíneas do gênero Cynodon com uso de diferentes metodologias. Acta Scientiarum, v.22, p.761-764, 2000.

SILVA, J.S.; QUEIROZ, A.C. Análise de alimentos: métodos químicos e biológicos. 3.ed. Viçosa: UFV, 2002. 235p.

TILLEY, J.M.A.; TERRY, R.A. A two-stage technique for the in vitro digestion of forage crops. J. Br. Grassl. Soc., v.18, p.104-111, 1963.

TRAXLER, M.J.; ROBERTSON, J.B.; VAN SOEST, P.J. e al. A comparison of methods for determining IVDMD a three periods using the filter bag technique versus conventional methods. J. Dairy Sci., v.78, suppl. 1, p.274, 1995.

VALADARES FILHO, S.C.; ROCHA JÚNIOR, V.R.; CAPPELLE, E.R. Tabelas brasileiras de composição de alimentos para bovinos. Viçosa: UFV, 2000. 297p.

VOGEL, K.P.; PEDERSEN, J.F.; MASTERSON, S.D. et al. Evaluation of a filter bag system for NDF, ADF, and IVDMD forage analysis. Crop Sci., v.39, p.276-279, 1999.

WILMAN, D.; ADESOGAN, A. A comparison of filter bag methods with conventional tube methods of determining the in vitro digestibility of forages. Anim. Feed Sci. Technol., v.84, p.33-47, 2000. 